\title{
O CÃO E O CURUMIM: O ENCONTRO COMO PROCESSO EDUCATIVO
}

Maria Edith Romano Siems-Marcondes ${ }^{(*)}$

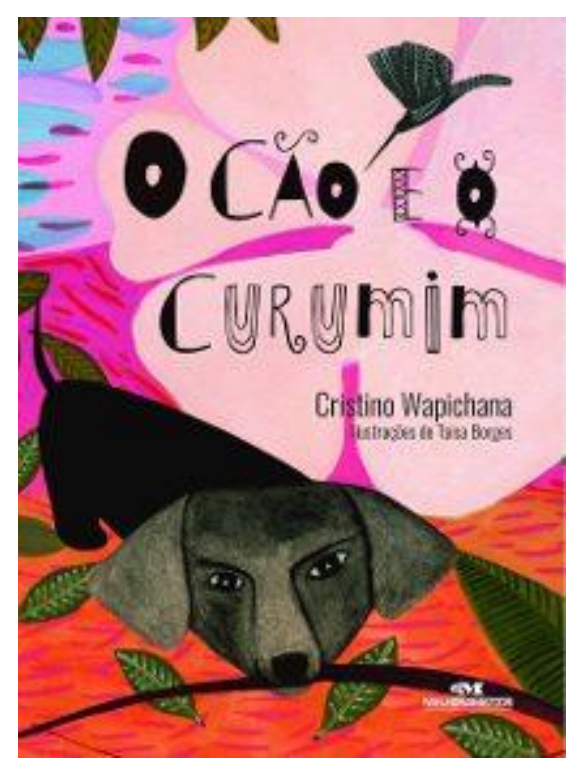

WAPICHANA, Cristino. O Cão e o Curumim. Ilustrações de Taísa Borges. São Paulo: Editora Melhoramentos, 2018.

"Certas canções que ouço, cabem tão dentro de mim, que perguntar carece, como não fui eu quem fiz".

Ao concluir a leitura do texto de $O$ Cão e o Curumim de Cristino Wapichana, fui assolada pela incrível sensação do "como não fui eu quem fiz"1. Um primeiro olhar ao teor deste texto literário que se propõe a narrar uma história de amizade e lealdade entre um menino indígena e seu cão; que se desenvolve no cenário de uma tribo indígena, poderia fazer supor que a resposta poderia estar a priori dada: como não-indígena, caucasiana, terceira geração de migrantes europeus, portanto, herdeira dos que aqui chegaram como invasores para ocupar as terras indígenas, jamais poderia ser considerada "informada", ou apta a tratar da temática. Mas não é isso o que se estabelece na relação com o texto, cujo impacto é tão intenso que parece ter saído "do interior do meu interior"'2.

A aparente leveza do texto literário, que em perspectiva aligeirada poderia ser entendido como destinado ao público infanto-juvenil, seja pela temática, seja pelo cuidado na adoção de uma

\footnotetext{
${ }^{(*)}$ Pedagoga, mestre em Educação, Doutora em Educação Especial. Professora do Centro de Educação da Universidade Federal de Roraima.

${ }^{1}$ Trecho da música de Milton Nascimento "Certas Canções” constante no álbum Anima, de 1982.

2 Trecho da Música de Vander Lee “Aonde Deus possa me ouvir”, constante no álbum Vander Lee de 2003.
} 
linguagem clara, em sequência linear e temporal e com uma dinâmica ágil e recheada de pequenas aventuras, traduz com a profundidade que a simplicidade verdadeira engendra, a densidade das reflexões que envolvem esta geração de escritores indígenas que vem se apresentando na literatura brasileira.

Trata-se de uma obra extremamente relevante para o momento atual, demarcado pelo recrudescimento e tentativa de retirada dos parcos direitos já conquistados pelos povos indígenas. Não bastasse essa pertinência ao tempo histórico, a obra ainda nos confronta com as reflexões sobre as relações sociais, familiares e culturais destes povos que, a mais de cinco séculos, resistem e lutam pela preservação de suas identidades, culturas e formas peculiares de vida marcadas pela relação simbiótica com as outras formas de vida.

$\mathrm{O}$ autor, na apresentação do livro, nos encaminha a duas indicações aparentemente soltas. $\mathrm{O}$ texto é aberto com as frases: "Histórias que moram em mim" e "O sentido da existência está na cor do encontro". E é esta a tônica que nos direciona ao imergir no texto.

Cristino Wapichana é nascido em uma comunidade indígena da etnia Wapichana, que tem sua maior concentração no extremo norte brasileiro, no estado de Roraima. Seguindo a trilha que vem sendo aberta na produção de uma literatura indígena brasileira, Cristino vem se destacando mundialmente com sua obra, tendo recebido alguns dos maiores prêmios literários, como o brasileiro Jabuti, na categoria literatura infantil (2017), o Sueco, Peter Pan (2018) e o Selo White Revens da Biblioteca de Munique (2017), além de selos e prêmios da Fundação Nacional do Livro Infantil e Juvenil que destacam obras suas como Altamente Recomendáveis (2015 e 2017).

A narrativa se desenvolve em torno de Curumim e seu cotidiano na vida da aldeia, nas relações entre a família próxima: pai, mãe, avós e irmãos e os demais "parentes", modo tradicional como são percebidas as relações de partilha da existência com a comunidade ampliada.

Esse cotidiano, pautado pelas relações com os elementos da natureza e com os artefatos culturais que a comunidade produz para sua organização e subsistência, é narrado pela voz de Curumim que entremeia a leveza de banhos de rio e dos prazeres calorosos da vida na maloca com os perigos da vida na floresta: os bichos grandes, "os animais menores que são venenosos e mais difíceis de serem vistos e os lugares encantados que deixam os caçadores desorientados, fazendo-os andarem em círculos" (p. 31).

No centro da ação, a chegada de Minhayda'y ou Amigo, o cãozinho trazido pelo pai no retorno de uma caçada e seu processo de incorporação na vida da aldeia, também como "caçador". 
A primeira ideia que parece conduzir a produção de Cristino Wapichana, é dar materialidade ao que ele traduz como "Histórias que moram em mim" e que são permeadas pelas marcas de sua ancestralidade. E é, no mergulho nessa ancestralidade que vemos uma possível explicação para o sentimento do "como não fui eu que fiz" que nos assola ao final da leitura.

A obra é uma clara expressão da clássica afirmação de Leon Tolstoi: "Se queres ser universal, começa por pintar a tua aldeia”. Na profundidade da narrativa dos pensamentos de Curumim, nos vemos lançados em reflexões contundentes que remetem a questões universais ao humano.

Esse mergulho é tão intenso na experiência humana que envolve o cotidiano de uma aldeia, nas peculiaridades da relação de parentesco amplo como entendida pelos povos indígenas, na dinâmica das relações homem-natureza que marca a trajetória de assegurar a sobrevivência e a riqueza da vida espiritual e cultural das comunidades, que acabamos, por tomar contato com o universal dos sentimentos que nos envolve a todos como humanidade.

O segundo mote de condução da obra declarado pelo autor é "O sentido da existência está na cor do encontro". E este se explicita na narrativa de pensamentos que brotam no brincar de Curumim com um raio de sol:

Acho que o sentido da existência está na essência dos encontros. São os encontros que nos permitem viver momentos especiais, inesquecíveis, que nos fazem sentir parte do outro e do mundo. (p. 43).

E é esse encontro com o diverso, com suas mitologias, seus sentimentos e suas formas culturais de relação com a natureza e com o outro - animal, vegetal ou do universo espiritual, que a obra se apresenta como essencial para se pensar a educação.

Em um longo trecho que aqui destacamos, Curumim, referindo-se ao avô contador de histórias, vai destacar elementos significativos dos sentidos do educar na educação indígena:

Havia outros velhos que contavam histórias e nos incentivavam a ler tudo ao nosso redor. A leitura pertence a todos, e todos são responsáveis por ensinar a ler e a escrever. Pais, tios, primos ensinam leituras diferentes para que todos sejam capazes de ler o mundo, de ser observadores e coletores de novas informações, de saber usar o conhecimento diariamente em atividades cotidianas como caçar, pescar, plantar e nadar, além de conhecer bem a mata e as águas dos rios. A leitura nos livra de perigos e acidentes. (p. 37-38). 
Impossível não observar nesse relato a presença do pensamento de Freire $^{3}$ (1989) que ao discutir a importância do ato de ler, destaca a precedência da leitura do mundo sobre a leitura da palavra. E não é difícil supor que o músico, escritor e contador de histórias Cristino Wapichana tenha tido acesso a este referencial teórico e contato com a obra de nosso mundialmente mais aclamado educador ${ }^{4}$. É entretanto, a indianidade que marca em profundidade sua obra e as reflexões que remetem à educação indígena.

Essa educação, que se dá na constância das relações sociais, nas práticas laborais do cotidiano, que é partilhada por todos os membros da aldeia; educação em contexto social, sem ser reduzida ao universo da escolarização, é demarcada pela perspectiva de uma formação integral, que privilegia a tradição oral e a ação intencional e coletiva dos adultos da comunidade junto a todas as crianças e jovens.

No desenvolvimento da ação, uma travessura infantil leva à queima total da casa que guardava as sementes e suprimentos da familia. E no relato do como as crianças agem e como os parentes reagem, vemos um outro aspecto da educação indígena que nos aparece no registro de estudos antropológicos que se dedicam a demarcar como se dão os processos de educação indígena: a ausência de práticas de punição de crianças. Assim nos conta Curumim, que após o incêndio:

Vovô e vovó estavam lá. Não havia tristeza, desespero ou decepção neles. Sabiam que curumins são arteiros. Que o medo e o susto que meu irmão e eu havíamos passado eram mais fortes que qualquer punição. As lembranças que iríamos carregar não nos deixariam mais brincar com fogo perto de cobertura de palhas. (p. 55).

E na sequência da narrativa, as crianças são envolvidas no processo de construção de um novo telhado de palha, partilhando das várias etapas, sob condução dos mais experientes, aprendendo desde o aguardar a condição correta da lua para colheita, até os demais cuidados necessários para que esta colheita, feita também coletivamente, ocorra com a segurança e qualidade adequada, respeitada a medida de força e capacidade de cada um.

Não bastasse o mérito que a narrativa tem de nos apresentar com profundidade e clareza a processos tradicionais de educação indígena, a obra ainda se destaca pelo seu potencial de

\footnotetext{
${ }^{3}$ FREIRE, Paulo. A importância do ato de ler: em três artigos que se completam. 23. ed. São Paulo: Autores Associados; Cortez, 1989.

${ }^{4}$ Segundo dados da London School of Economics, em levantamento realizado no ano de 2016, Freire é citado 72.359 vezes, atrás somente do filósofo americano Thomas Kuhn (81.311) e do sociólogo, também americano, Everett Rogers (72.780).
} 
dinamizador de discussões em relação à cultura, ao respeito à ancestralidade e às práticas culturais de uma outra infância, em que uma outra educação é possível.

E não se trata aqui de um olhar estrangeiro, mas do relato de um menino indígena que se fez homem e se faz grande, como escritor e em diferentes linguagens artísticas praticadas na comunidade envolvente.

Um excelente exercício a representar o "Nada sobre nós, sem nós"5 também no contexto das diferentes representações étnicas que nos caracterizam enquanto país e enquanto sociedade e que precisam ser conhecidas, no princípio de que não é possível respeitar e valorizar aquilo que não se conhece.

Submetido em: 12 defevereiro de 2019

Aprovado em: 15 de março de 2019

\footnotetext{
${ }^{5}$ Compreendemos que este lema tem sua origem nos movimentos sociais das pessoas com deficiência, mas estendemos aqui sua aplicação à questões étnicas por entender que aqui também é pertinente a protagonização que se expande, de diferentes grupos étnicos tratando diretamente de suas demandas e realidades.
} 